\title{
Correction to: Comparison of the arrhythmogenic substrate for ventricular tachycardia in patients with ischemic vs non-ischemic cardiomyopathy — insights from high-density, multi-electrode catheter mapping
}

\author{
Yasuhito Kotake $^{1} \cdot$ Chrishan J. Nalliah $^{1} \cdot$ Timothy Campbell $^{1} \cdot$ Richard G. Bennett $^{1} \cdot$ Samual Turnbull $^{1}$. \\ Saurabh Kumar ${ }^{1}$ (D)
}

(c) Springer Science+Business Media, LLC, part of Springer Nature 2022

Correction to: Journal of Interventional Cardiac Electrophysiology https://doi.org/10.1007/s10840-021-01088-7

In Fig. 1 of this article "F: Pace map" should have been "H: Pace map"; the figure should have appeared as shown below.

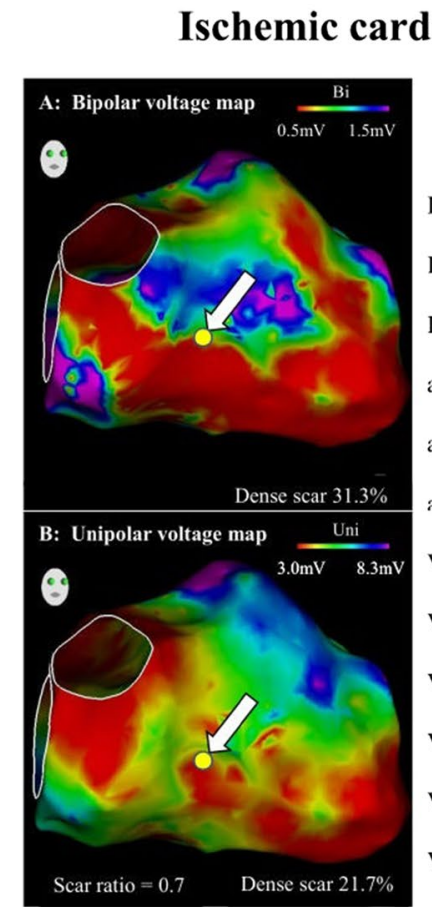

\section{diomyopathy}

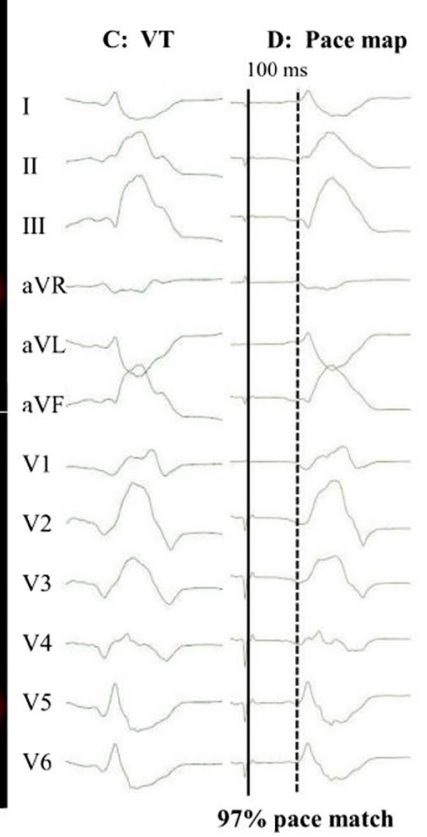

The original article can be found online at https://doi.org/10.1007/ s10840-021-01088-7.

Saurabh Kumar

Saurabh.Kumar@health.nsw.gov.au

1 Department of Cardiology, Westmead Hospital, Westmead,

Applied Research Centre, University of Sydney,

Hawkesbury, Road, Westmead, NSW 2145, Australia

\section{Non-ischemic cardiomyopathy}
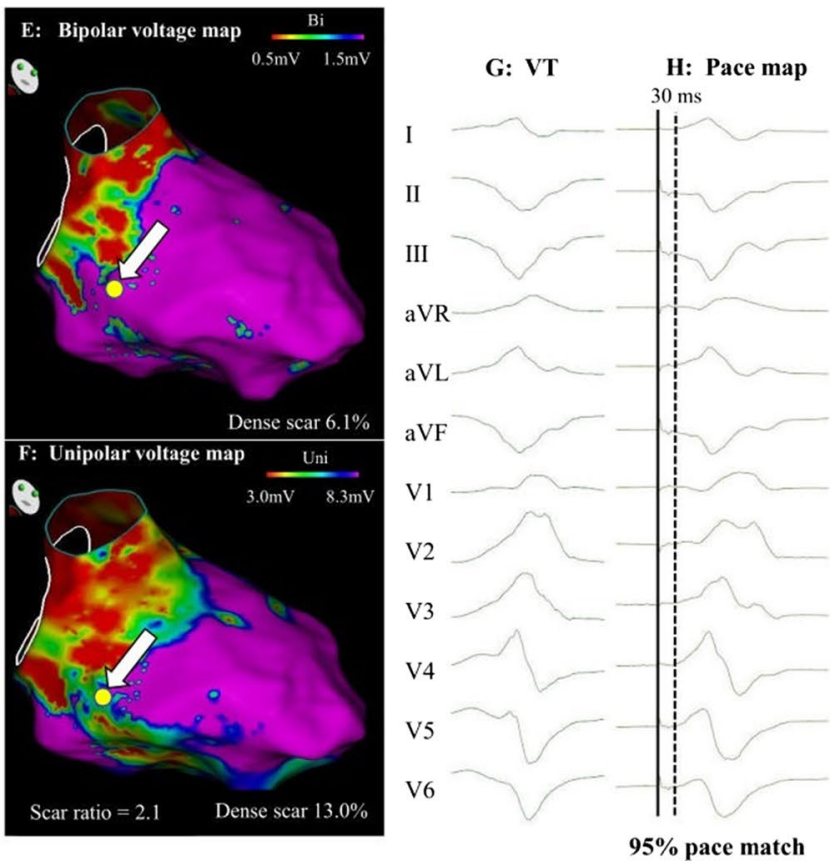

The original article has been corrected.

Publisher's note Springer Nature remains neutral with regard to jurisdictional claims in published maps and institutional affiliations. 